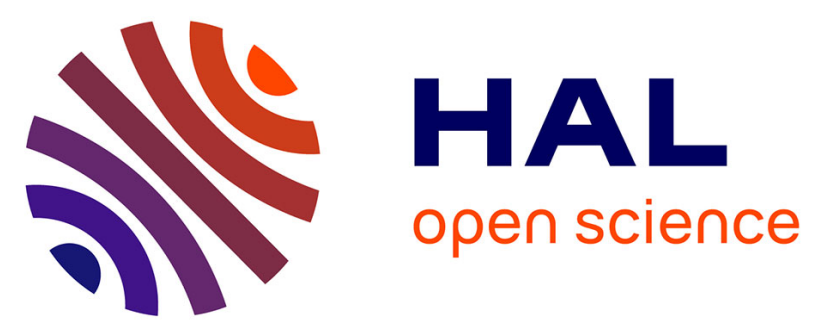

\title{
Influence of textile treatment on mechanical and sorption properties of flax/epoxy composites
}

Zine Eddine Cherif, Christophe Poilâne, Thierry Falher, Alexandre Vivet, Nabil Ouail, Bessem Ben Doudou, Jun Chen

\section{- To cite this version:}

Zine Eddine Cherif, Christophe Poilâne, Thierry Falher, Alexandre Vivet, Nabil Ouail, et al.. Influence of textile treatment on mechanical and sorption properties of flax/epoxy composites. Polymer Composites, 2013, 34 (9), pp.1761 - 1773. 10.1002/pc.22580 . hal-03347182

\author{
HAL Id: hal-03347182 \\ https://hal.science/hal-03347182
}

Submitted on 17 Sep 2021

HAL is a multi-disciplinary open access archive for the deposit and dissemination of scientific research documents, whether they are published or not. The documents may come from teaching and research institutions in France or abroad, or from public or private research centers.
L'archive ouverte pluridisciplinaire HAL, est destinée au dépôt et à la diffusion de documents scientifiques de niveau recherche, publiés ou non, émanant des établissements d'enseignement et de recherche français ou étrangers, des laboratoires publics ou privés. 


\title{
Influence of Textile Treatment on Mechanical and Sorption Properties of Flax/Epoxy Composites
}

\author{
Zine Eddine Cherif, ${ }^{1}$ Christophe Poilâne, ${ }^{1,2}$ Thierry Falher, ${ }^{3}$ Alexandre Vivet, ${ }^{1}$ Nabil Ouail, ${ }^{1}$ Bessem Ben \\ Doudou, ${ }^{1}$ Jun Chen ${ }^{1}$ \\ AQ1 ${ }^{1}$ CIMAP, UMR6252 CNRS-CEA-ENSICAEN-Université de Caen Basse-Normandie, F-14032 CAEN, France
}

${ }^{2}$ LAUM UMR6613 CNRS-Université du Maine, F-72085 Le Mans, France

${ }^{3}$ ISPA, Pôle Universitaire Montfoulon, 61250 Damigny, France

\begin{abstract}
The aim of the present work is to study the effect of conventional textile treatments of woven flax on the mechanical properties and the water sorption of flax/ epoxy composites. The flax fabrics are standard $2 / 2$ twills. Various treatments are carried out on fabric such as mercerization, bleaching, and leaching for long fibers or on yarn such as leaching for short fibers. A model, based on a modified rule of mixture applied to composite reinforced with woven fabric, is developed to include the effect of fiber and porosity volume fractions on composite stiffness and strength. Most treatments improve tensile stiffness and strength of flax/epoxy composite and reduce composite water sorption. We prove by X-ray fluorescence analysis, thermogravimetric analysis, and tensile tests of dry fabric that it is due to an improvement in the interfacial bonding between fibers and matrix. The best performances are achieved with bleaching and mercerization treatment. The weakest performances are obtained with the composites made with leached yarns. POLYM. COMPOS., 00:000-000, 2013. (c) 2013 Society of Plastics Engineers
\end{abstract}

\section{INTRODUCTION}

Natural fibers, especially flax fibers, have shown their capacity to be a good candidate as reinforcement of composite materials through a combination of properties: relatively high-specific strength and modulus, low density, material renewable, and low environmental impact $[1,2]$. Nevertheless, these fibers have also some disadvantages: they are hydrophilic and have a low thermal resistance $[3,4]$. Furthermore, the quality of these fibers varies according to the local climate and the nature of the ground

Correspondence to: C. Poilâne; e-mail: christophe.poilane@unicaen.fr Contract grant sponsor: LINEO NV Company.

DOI 10.1002/pc.22580

Published online in Wiley Online Library (wileyonlinelibrary.com).

(c) 2013 Society of Plastics Engineers
[1,5]. Moreover, flax fiber has a structure which can be compared to a composite material composed of helical cellulose fibrils embedded in a matrix of polymers (hemicelluloses, pectin, and lignin) $[5,6]$.

Industrial applications of composites reinforced with flax fibers already exist as tennis racket commercialized by Artengo ${ }^{\circledR}$. However, industrial applications of flax composites are still limited because of their low performances due to the incompatibility between the hydrophobic resin and the hydrophilic fiber [2-7]. Therefore, in addition to the intrinsic properties of fibers, mechanical properties, and water sorption of natural fiber-reinforced composites largely depend on the adhesion between the fibers and the matrix [8]. This interface can be improved by various chemical and physical methods $[9,10]$. Van de Weyenberg et al. [7] have reported the beneficial effect of several kinds of treatments such as dissolution by alkalization, silane coating, and impregnation with a dilute epoxy resin on the mechanical properties of flax/epoxy composite. Furthermore, several articles have been published about the positive effect of various chemical treatments on the properties of composites based on different kind of natural fibers such as jute/biopol [11], coir, and oil palm fiber-reinforced polyester composite [12]. Sreekumar et al. [13] have investigated the effect of various chemical and physical treatments, such as mercerization and heating at $100^{\circ} \mathrm{C}$ on the mechanical properties and water sorption of sisal/polyester composites. They found an enhancement of flexural and tensile mechanical properties and an improvement in the water sorption resistance. Arbelaiz et al. [14] have reported that the use of a coupling agent (maleated polypropylene) improves the mechanical properties and decreases the rate of water uptake of short flax/polypropylene composites.

All these studies focused on the treatment effect of natural short fibers or unidirectional long fiber reinforcement on composite properties. However, there are still 
few studies on the treatment of long woven flax reinforcements (yarn or fabric). Woven fabrics are attractive as reinforcements for composite materials. The potential of this kind of reinforcement can be summarized by their excellent handiness compared to nonwoven counterparts and their higher mechanical properties for the interlaminar and interfacial strength [15].

In the present work, textile composites based on flax fiber and epoxy resin have been investigated. The flax fabrics are 2/2 twills and they are made with yarn instead of the more usual tow. The work was focused on the effect of conventional textile treatments on woven flax reinforcement, called pretreatments. For that, the relationships between composite manufacturing techniques, mechanical properties and water sorption characteristics have been investigated. Moreover, to better understand macroscopic results, thermogravimetric analysis (TGA), elemental analyses by X-ray fluorescence (XRF) and tensile tests on dry fabric samples, and scanning electronic microscopy (SEM) observations on composite samples was performed.

\section{EXPERIMENTAL PROCEDURES}

\section{Material}

The prepregs used to elaborate the composites have been supplied by the LINEO NV Company [16]. All the five studied prepregs consist of weight controlled $2 / 2$ twill fabric impregnated by an epoxy resin. Transformation of flax fibers into flax/epoxy resin prepregs was made in several steps: spinning of flax fibers $\left(258 \mathrm{~m}^{-1}\right.$, $7.2 \mathrm{Nm}$, diameter $0.58 \mathrm{~mm}$ ), weaving of fabric, textile treatment (so-called pretreatment and applied before or after the weaving), and impregnation of fabric. The linen fabrics reach the impregnate line (in roll form) after the pretreatment. The impregnation steps are the following: drying fabrics, compatibilization treatment of fabrics (which can be compared with the sizing treatment of glass fibers), final impregnation of fabrics, interleaving between two polyethylene films. The entire process is carried out continuously. The major difference between the prepregs is the reinforcement pretreatment.

The fibers are not subjected to any particular selection. During the first step (yarn spinning), except for the leached yarn product, the fibers are successively scutched,

F1 hackled and spinned to form a yarn (Fig. 1a). The spinning technique used is the flax semiwet spinning, where yarns are only moistened on their external surface. The "leached yarn" product is different from the other fabrics. This product is made of tows which result from scutching and hackling. The tows are then leached in a specific bath during the spinning process. This kind of spinning is called flax wet-spinning. After spinning, all the yarns are woven in the form of $2 / 2$ twill fabric (Fig. 1b). The weight is set up to $300 \mathrm{~g} \mathrm{~m}^{-2}$ for all the fabrics with ten

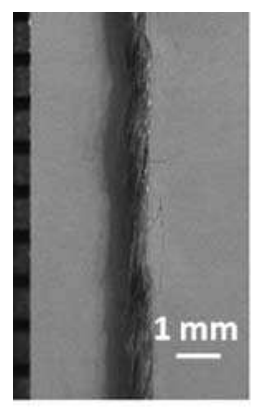

(a)

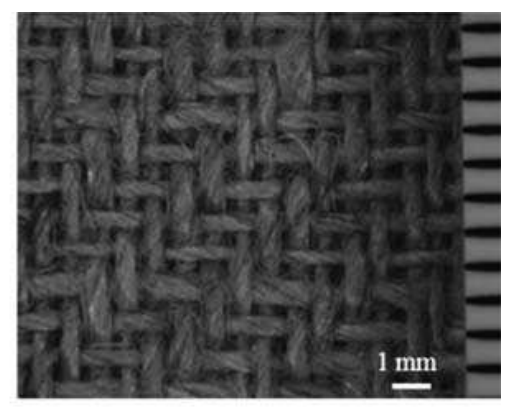

(b)
FIG. 1. Optical photography of flax yarn and twill $2 / 2$ fabric made with flax yarn: (a) flax yarn and (b) flax woven. [Color figure can be viewed in the online issue, which is available at wileyonlinelibrary.com.]

yarns by centimeter for both the warp and the weft direction.

After weaving, the fabrics made with yarns coming from the flax semiwet spinning are subjected to pretreatment: "leaching," "bleaching," or "mercerization" (see Table 1). Therefore, for a composite application, we compare four pretreated fabric intended for a textile purpose with an untreated fabric. The leaching treatment is an alkaline boiling off. The mercerizing treatment is done with sodium hydroxide. The bleaching treatment is done with a combination of hydrogen peroxide and sodium hypochlorite. These pretreatments are classical alkali treatments used in the textile industry to clean fabrics and thus facilitate the finishing process [17].

Pretreatments lead to a slight modification of the fabric weight. First, some components of fibers as pectins could be degraded by pretreatments, consequently the yarn linear mass decreases. Second, on the opposite, pretreatments could increase the fabric surface mass by shrinking warp and weft yarns. To optimize the impregnation of the hydrophilic flax fibers with the hydrophobic epoxy resin, the woven fabrics undergo a compatibilization treatment patented by LINEO NV [18]. Finally, the fabrics are impregnated by an epoxy resin especially formulated for prepregs (Hunstman Araldite LY5150/Aradur 5021/Hardener XB 3471) [19].

\section{Composite Elaboration}

The composite materials were prepared by two different processes: hot platen press and autoclave. Laminates were produced with seven layers of prepreg fabrics for hot platen press and six layers for the autoclave process. Even if the $2 / 2$ twill fabric is balanced with the same amount of warp as weft yarns; special care has been always taken to align the warp yarns in the main direction.

Hot Platen Press. Seven layers of fabric $(200 \mathrm{~mm} \times$ $110 \mathrm{~mm}$ ) are stacked and cured between the two platens of a heated press [20]. The platen surface is $240 \mathrm{~mm} \times$ $150 \mathrm{~mm}$. To obtain a reinforcement volume fraction $V_{\mathrm{r}}$ of 
TABLE 1. Details of the twill $2 / 2$ fabrics used for the preparation of the composites.

\begin{tabular}{lcll}
\hline Product name & $\begin{array}{c}\text { Basic weight, } \\
g_{\mathrm{f}}\left(\mathrm{g} \mathrm{m}^{-2}\right)\end{array}$ & Fiber type & Pretreatment \\
\hline Untreated & 300 & Long fibers & No treatment \\
Leached & 277 & Long fibers & Leaching of fabric with a detergent \\
Mercerized & 302 & Long fibers & Bleaching of fabric with $\mathrm{H}_{2} \mathrm{O}_{2}$ and NaClO \\
Bleached & 267 & Short fibers & Leaching of yarns with a detergent \\
Leached yarns & 316 & & Labric \\
\hline
\end{tabular}

about $50 \%, 12$ wedges of $2.5 \mathrm{~mm}$ thickness are included between the two platens. The curing cycle begins with a first stage of $30 \mathrm{~min}$ at $80^{\circ} \mathrm{C}$, to reduce the resin viscosity and to promote its spread, followed by a second stage at $130^{\circ} \mathrm{C}$ for $60 \mathrm{~min}$, which allows final curing and internal cross-linking of resin. The final sample thickness varies from 2.6 to $2.7 \mathrm{~mm}$.

Autoclave. The prepreg fabrics are stacked to form a six ply laminate on a highly rigid plate $(370 \mathrm{~mm} \times 330$ $\mathrm{mm}$ ) and placed in a vacuum polymer bag. The laminates are cured in an autoclave after a single-stage cycle at $120^{\circ} \mathrm{C}$ during $150 \mathrm{~min}$. The applied vacuum and the external pressure are, respectively, set at 2 and $300 \mathrm{kPa}$. The final thickness varies from 2.7 to $3.2 \mathrm{~mm}$.

\section{Methods}

Tensile Test. Tensile tests on dry fabrics are conducted on an electromechanical testing machine (MTS Criterion $^{\mathrm{TM}}$ Model 43) fitted with a 500-N load cell. All the tests (five by fabric) were performed at $23^{\circ} \mathrm{C}$ and relative humidity $50 \%$ with a crosshead speed of $2.0 \mathrm{~mm} \mathrm{~min}^{-1}$. Samples dimensions are $11 \mathrm{~mm} \times 70 \mathrm{~mm}$. They comprise 10 yarns in warp direction (tensile direction) by 37 $\mathrm{mm}$ long between jaws. Full strain of sample was measured from the crosshead displacement and the initial length of the samples. The average stress in the yarn is calculated by dividing the tensile strength by the average section of the 10 warp yarns. This section is measured after testing by sampling and weighing of tested yarns using the equation:

$$
A=\frac{m}{\rho_{\mathrm{r}} \cdot l}
$$

where $A$ is the area of the section of ten yarns, $m$ is the weight of the ten yarns, $\rho_{\mathrm{r}}$ is flax density, and $l$ is the initial yarn length. For all products, density used for flax is 1.54 .

Tensile tests on composites are conducted on a servohydraulic testing machine (Instron 8801) fitted with a $100-\mathrm{kN}$ load cell. All the tests were performed at room temperature with a crosshead speed of $2.0 \mathrm{~mm} \mathrm{~min}^{-1}$ (according to the standard ISO 527-4). The elongation is measured with an extensometer of a gauge length of 50 $\mathrm{mm}$ and a precision of $0.5 \%$. Specimen length and width are, respectively, equal to 250 and $20 \mathrm{~mm}$. Specimen thickness depends on material type (fabric weight and composite elaboration process). The tensile direction is aligned with fabric warp direction. Indeed, a comparison conducted on the same flax/epoxy composite (untreated $2 / 2$ twill fabric) has shown identical properties in warp and weft direction (see Fig. 3b) [21].

SEM Observations. Section and fracture surfaces of composite specimens were observed by means of a scanning electron microscope. Before observations, surfaces are gold-coated in a sputtering chamber (Cressington Carbon Coater 208) to improve composite electrical conductivity and to limit electrical charging. The thickness of the gold coating was about $40 \mathrm{~nm}$. Microscopic observations have been done at $25 \mathrm{kV}$ with a Princeton Cambridge Gamma-Tech SEM.

Sorption Test. Measurement of water sorption of a composite material has been performed using a gravimetric analysis. The method consists in measuring the content of absorbed water as a function of exposure time. The specimen is a square of $200 \mathrm{~mm}$ side. First of all, samples are dried at $103^{\circ} \mathrm{C}$ for $24 \mathrm{~h}$ to remove all traces of moisture within the material. To avoid moisture sorption of the four edges of the samples, they were covered with a layer of high temperature silicone. After preparation, the specimens were immersed into a water bath at a controlled temperature of $20^{\circ} \mathrm{C}$. The samples were weighted at regular intervals to determine the water sorption rate in time. It should be noted that before weighing, the surface of the specimens was meticulously dried with tissue. The water sorption rate $M_{t}$ at time $t$ can be expressed as follow:

$$
M_{t}=\frac{W_{t}-W_{0}}{W_{0}}
$$

where $W_{0}$ is the weight of dried specimen and $W_{t}$ is the weight of the wet specimen at time $t$.

Thermogravimetric Analysis. All the fabric samples were cleaned for $15 \mathrm{~min}$ in demineralized water at $45^{\circ} \mathrm{C}$ before the XRF and TGA tests. The thermogravimetric measurement has been achieved on a TGA7 Perkin Elmer apparatus and analyzed on a TAC7/DX analyzer Perkin Elmer. The mean weight of the tested samples was $8 \mathrm{mg}$. 
The thermal cycle includes heating from 50 to $900^{\circ} \mathrm{C}$ at $10^{\circ} \mathrm{C} \mathrm{m^{-1 }}{ }^{-1}$ under pure and dry nitrogen at $45 \mathrm{ml} \mathrm{min}^{-1}$, an isotherm for $1 \mathrm{~min}$ under nitrogen, and an isotherm of 10 min under dry air.

XRF Analysis. XRF analyses were conducted on fabric samples of flax using a Philips PW 2404 X-ray spectrometer with a $\mathrm{Rh}$ anode and a 27-mm diameter collimator mask. Fabrics were directly analyzed with calibration using in-house polymer standards for $\mathrm{C}, \mathrm{O}$, and $\mathrm{N}$ elements and standard reference materials for other elements.

\section{RESULTS}

\section{Fiber and Porosity Volume Fractions}

Natural fibers are relatively more difficult to be impregnated by resin than synthetic fibers (glass or carbon). Moreover, the presence of porosities in composite laminate is known to dramatically decrease the mechanical and the sorption properties $[22,23]$. In addition to the reinforcement volume fraction $V_{\mathrm{r}}$, the porosity volume fraction $V_{\mathrm{p}}$ must be taken into account during performance analysis of natural fiber composites.

After elaboration, the composite plate is weighted and measured to obtain its weight $W_{\mathrm{c}}$, its thickness $h$, its length $L$ and its width $w$. The knowledge of the basis weight of fabrics $g_{\mathrm{r}}$, the number of layers in the laminate $n_{\text {layer}}$, the reinforcement density $\rho_{\mathrm{r}}=1.54$ [22] (supposed to be equal to fiber density) and the matrix density $\rho_{\mathrm{m}}=1.2$ [19], allows calculating the volume fractions of the three constituents:

$$
V_{\mathrm{r}}=\frac{\text { Volume }_{\text {yarn }}}{\text { Volume }_{\text {composite }}}=\frac{\frac{W_{\mathrm{r}}}{\rho_{\mathrm{r}}}}{L \cdot w \cdot h}=\frac{\frac{n_{\text {layer }} \cdot g_{\mathrm{r}} \cdot L \cdot w}{\rho_{\mathrm{r}}}}{L \cdot w \cdot h}=\frac{n_{\text {layer }} \cdot g_{\mathrm{r}}}{h \cdot \rho_{\mathrm{r}}}
$$

$$
\begin{gathered}
V_{\mathrm{m}}=\frac{\text { Volume }_{\text {matrice }}}{\text { Volume }_{\text {composite }}}=\frac{\frac{W_{\mathrm{m}}}{\rho_{\mathrm{m}}}}{L \cdot w \cdot h}=\frac{\frac{W_{\mathrm{c}}-W_{\mathrm{r}}}{\rho_{\mathrm{m}}}}{L \cdot w \cdot h}=\frac{W_{\mathrm{c}}-W_{\mathrm{r}}}{\rho_{\mathrm{m}} \cdot L \cdot w \cdot h} \\
V_{\mathrm{p}}=1-\left(V_{\mathrm{r}}+V_{\mathrm{m}}\right) .
\end{gathered}
$$

Final uncertainties on $V_{\mathrm{p}}, V_{\mathrm{r}}$, and $V_{\mathrm{m}}$ values are estimated with the uncertainties on each initial parameter and using the uncertainty propagation method.

In the case of composite prepared with hot platen press, the reinforcement volume fraction varies from 46 to $53 \%$ with a mean value around $50 \%$ (Fig. $2 \mathrm{a}$ ). It is higher than that produced with autoclave process; the mean value is then $39 \%$ with a minimum of $38 \%$ and a maximum of $43 \%$. Concerning the porosity volume fraction, it seems to be independent of the textile pretreatment and the production process (Fig. 2b). Indeed, for all the composites made with long fiber yarn, the porosity volume fractions are close, with a mean value of $12.2 \%$. The result for untreated flax-reinforced composite manufactured with the autoclave process differs from this value. It shows a higher value than that obtained with the hot platen press (18.8 vs. 13.3\%). Moreover, the higher values of $V_{\mathrm{p}}$ obtained for the leached yarn composites is due to the nature of the yarns that are made of short fibers.

The important porosity volume fraction is due to the flax fabric structure. First, the fabrics are made of relatively uncompressible yarn instead of classical tow. Second, the filling rate of the woven fabric is relatively low (Fig. 1b).

\section{Mechanical Properties}

Mechanical Properties of composite. A typical strainstress curve of flax-reinforced composite is shown in Fig. 3a. No effect of the flax pretreatment on the global mechanical behavior is observed.

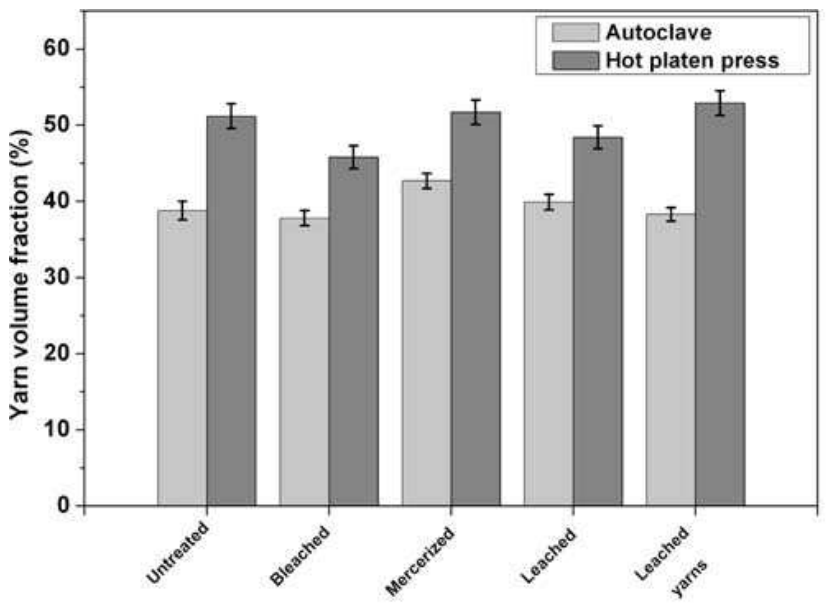

(a)

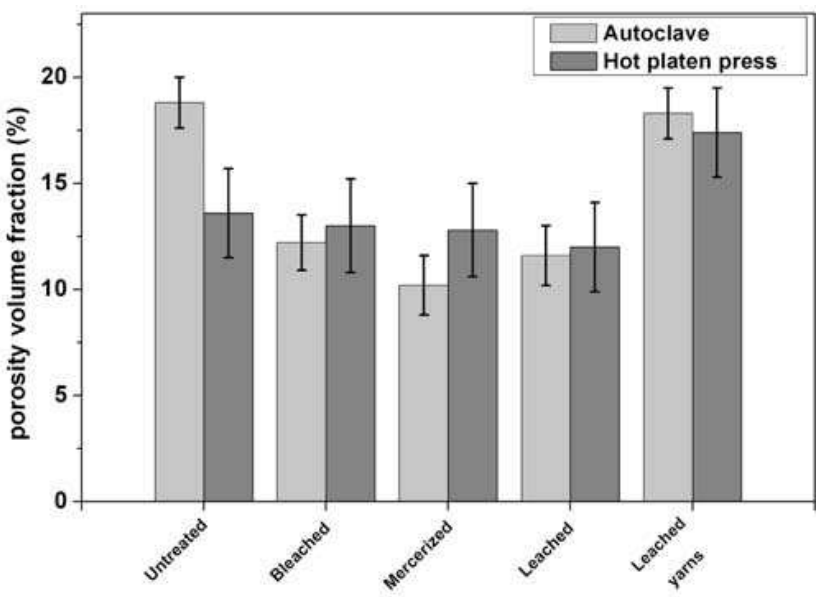

(b)

FIG. 2. Volume fractions of flax/epoxy composites for different pretreatments: (a) reinforcement fraction and (b) porosity fraction. 


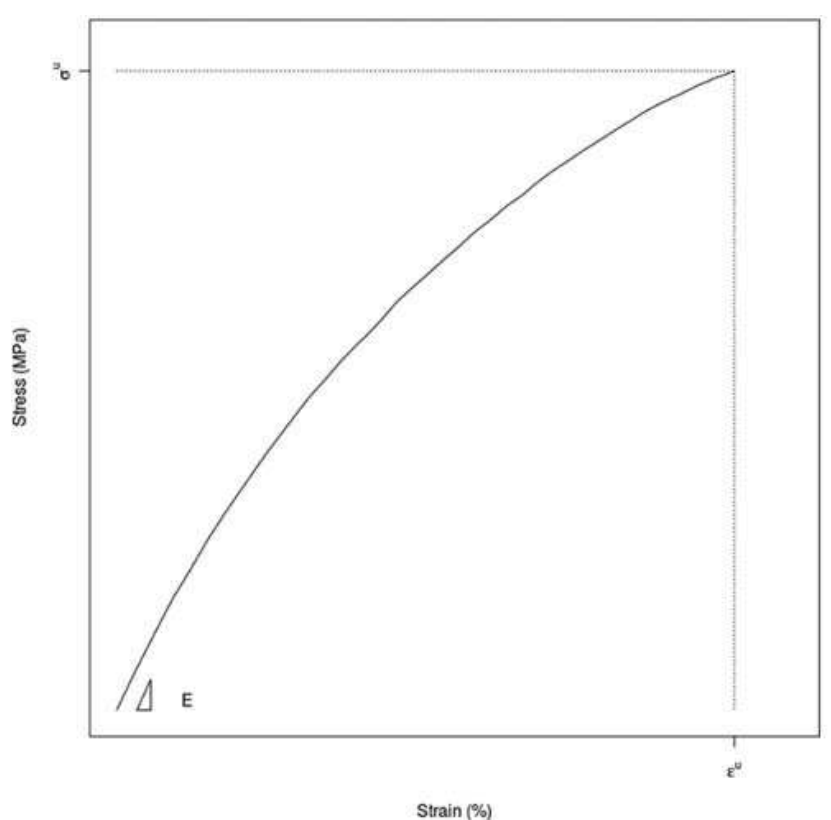

(a)

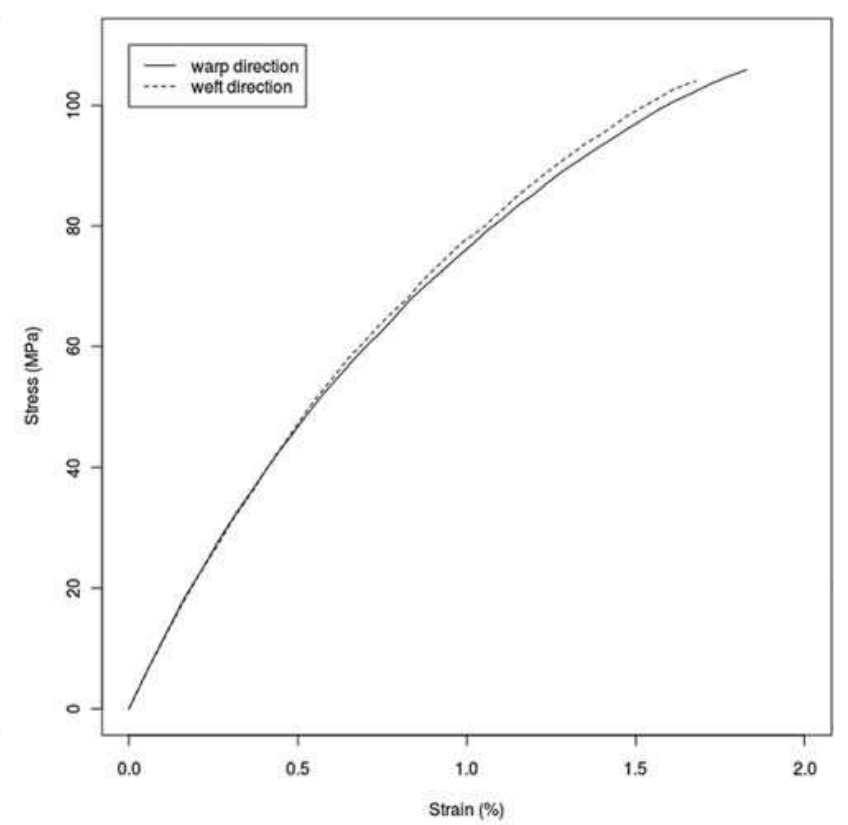

(b)

FIG. 3. Typical stress-strain curve of $2 / 2$ twill flax fabric-reinforced composite under tensile loading (untreated fabric): (a) used setup, $E$ is the modulus, $\sigma^{u}$ is the ultimate stress, $\varepsilon^{u}$ is the ultimate strain and (b) tensile curve in warp and weft direction.

The mechanical properties of composites produced F4 with both methods are given in Fig. 4. For a same pretreatment, we note that stiffness and strength are higher for the hot platen press than the autoclave process. That can be initially explained by the influence of the reinforcement volume fraction because it is higher for the composite manufactured with the hot platen press method. In addition to the yarn volume fraction, for the untreated reinforcement composite, the low values of stiffness and strength given by the autoclave process are also due to the high porosity volume fraction $\left(V_{\mathrm{p}}=18.8 \%\right)$. Nevertheless, the ultimate strain is higher for composites prepared with the hot platen press compared to that produced with the autoclave process. For both methods of composite production, pretreatments increase stiffness and strength of flax-reinforced composites except for leached yarns pretreatment. That is probably due to an improvement in the fiber-matrix interface. The best results are given by mercerization and bleaching pretreatment, with an enhancement of stiffness about 44 and $13 \%$ and an increase in the strength up to 55 and $29 \%$, for the autoclave process and hot platen press, respectively (same values for mercerization and bleaching). The improvement obtained with leaching pretreatment is estimated at 32 and $14 \%$ in stiffness and about 40 and $20 \%$ in strength, for the autoclave and hot platen press process, respectively. The weak performances (stiffness and strength) given by the composite made of a fabric with leached yarns are explained by the poor quality of the fibers (scutching and hackling tow). Furthermore, ultimate strain of flax/epoxy composite decreases after the fiber pretreatment. This strain decrease is probably due to a decrease in the fiber-matrix sliding, which may indicate an interface improvement.

Mechanical Properties of Dry Yarns. The observed changes in mechanical properties of composites, caused by the pretreatment, may result from a change in the reinforcement itself [24] or in the fiber-matrix interface [7]. Tensile tests on pretreated dry fabrics are summarized in Fig. 5. The used setup is given in Fig. 5a. Typical stressstrain curves for all the tested fabrics are given in Fig. 5 b. We show that all treatments reduced the ultimate strain (B point) and ultimate stress (C point). The apparent stiffness (slope of linear regression line) is related to these two parameters and mostly decreases, except for the bleached for which it increases slightly. The strength of fabrics relates to that of the warp yarns. Yarns strength comes from adhesion properties between technical fibers, intrinsic strength of fibers and average length of these fibers. Treatments can act on these three factors.

\section{Water Sorption}

Effect of Pretreatments. The water sorption tests were carried out only on the composites produced with the autoclave process. The water uptake curves for flax/epoxy composites with different pretreatments are shown in Fig. 6. All the pretreatments decrease water sorption of the flax/epoxy composites. Indeed, for pretreated flax- 


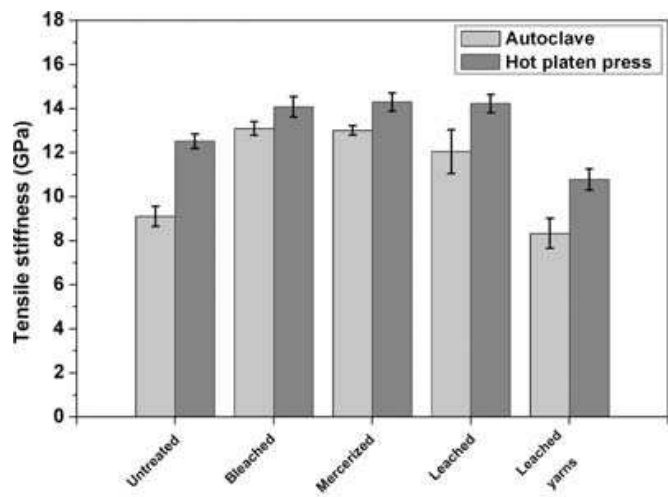

(a)

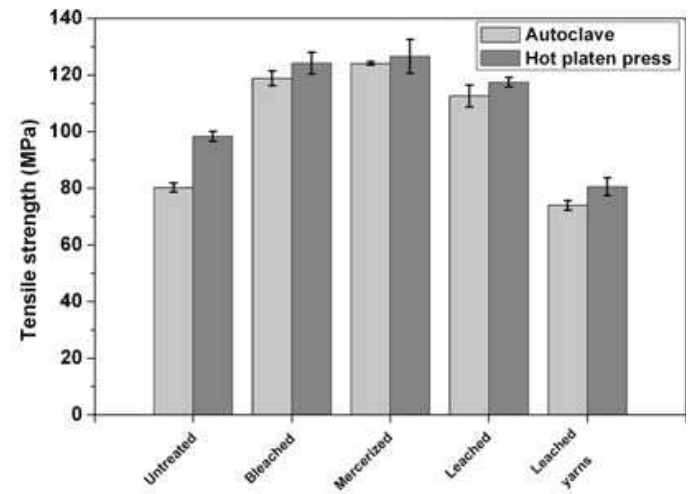

(b)

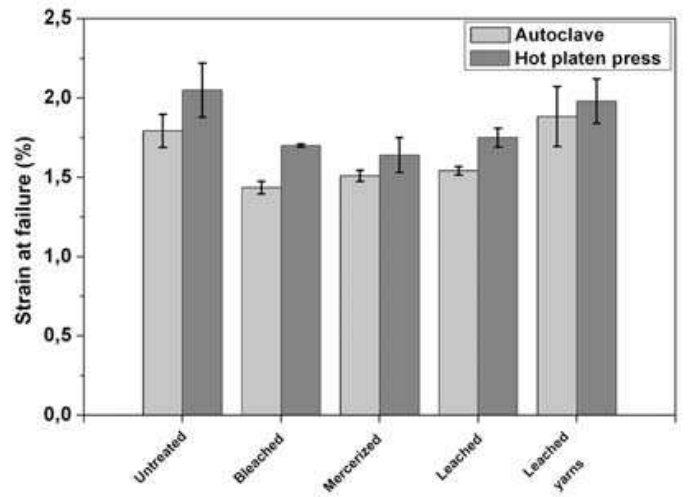

(c)

FIG. 4. Mechanical properties of pretreated flax/epoxy composite produced with hot platen press and autoclave process: (a) stiffness, (b) strength, and (c) ultimate strain.

reinforced composites, both initial rate of water uptake and equilibrium water uptake values decrease compared to untreated flax composite. The extent of the decrease varies and depends on the nature of the pretreatment. The best improvement in moisture resistance is observed for the bleached and the mercerized flax-reinforced composites. The leached fabric composite is at an intermediate level between untreated and mercerized/bleached fabric

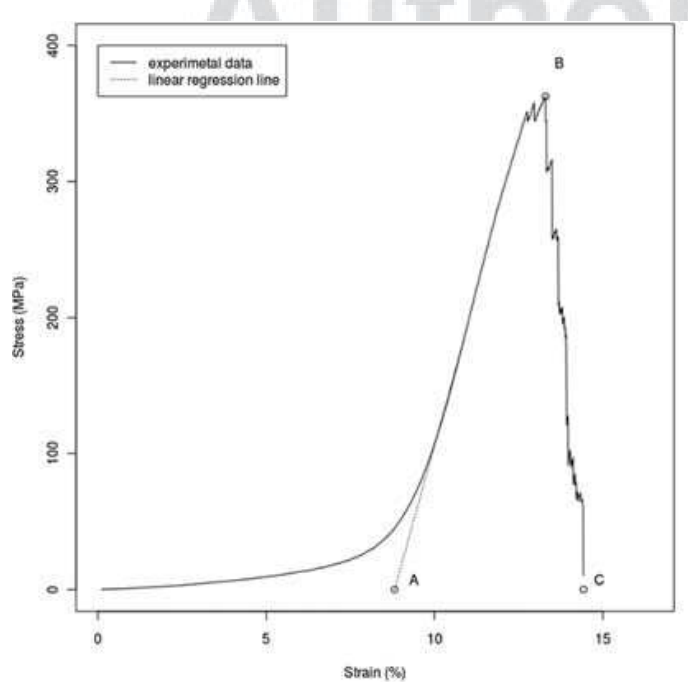

(a)

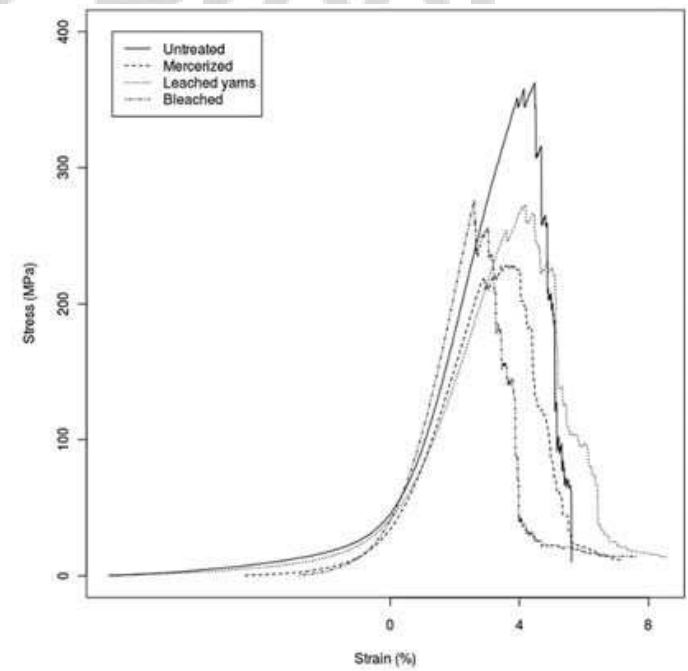

(b)

FIG. 5. Stress-strain curves of flax yarns under tensile loading: (a) used setup, A is the flax deformation beginning, $\mathrm{B}$ is the ultimate stress point, $\mathrm{C}$ is the ultimate strain point and (b) typical results for all the tested fabrics. 


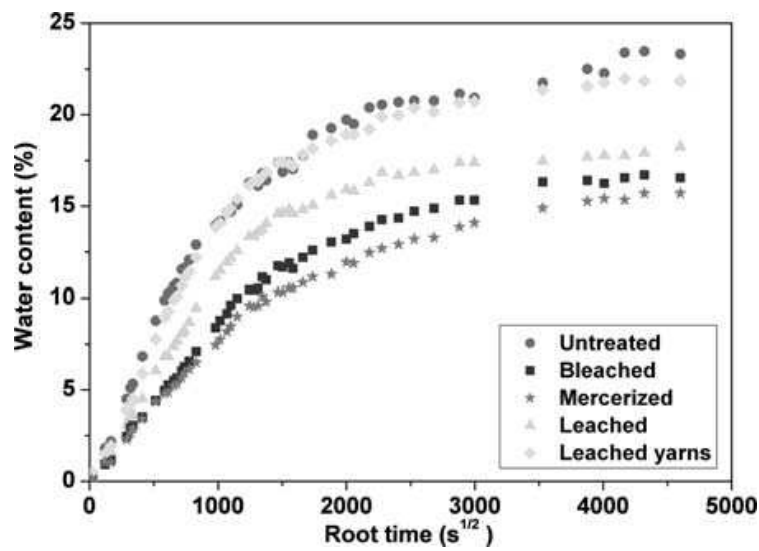

FIG. 6. Sorption curves showing moisture uptake at $20^{\circ} \mathrm{C}$ of flax/epoxy composite with different pretreatments. [Color figure can be viewed in the online issue, which is available at wileyonlinelibrary.com.]

composites. The leached yarns composite shows a slight decrease in the water sorption compared to untreated reinforcement composite.

Kinetics of Water Sorption. Moisture penetration into composite materials is conducted by one major mechanism called diffusion, and two minor mechanisms: capillarity and transport by microcracks. The first mechanism involves direct diffusion of water molecules into matrix and fibers. Capillarity implies flow of water molecules along the fiber-matrix interface caused by weak interfacial adhesion and debonding between fibers and matrix. Transport by microcracks includes both flow and storage of water in microcracks, porosity and other forms of microdamages formed during the compounding process or resulting from environmental effects and service conditions. Although, all these three mechanisms are active simultaneously when the composite material is exposed to moisture, the overall sorption behavior can be modeled efficiently only considering the diffusion mechanism.

Diffusion behavior in glassy polymers can be classified according to the relative mobility of the penetrant and of the polymer segments. This classification produces three different categories of diffusion behavior $[25,26]$ :

- Case I (or Fickian diffusion), in which the rate of diffusion is much less than that of the polymer segment mobility;

- Case II (and super case II), in which penetrant mobility is much greater than other relaxation processes;

- Non-Fickian or anomalous diffusion, which occurs when the penetrant mobility and the polymer segment relaxation are comparable. It is then an intermediate behavior between case I and case II diffusion.

These categories of diffusion can be distinguished by the shape of the sorption curve $[9,26]$ described by the equation:

$$
\frac{M_{t}}{M_{\mathrm{m}}}=k \cdot t^{n}
$$

where $M_{t}$ is the moisture content at time $t, M_{\mathrm{m}}$ is the moisture content at the equilibrium, $k$ is a constant characteristic of the polymer which indicates the polymer/ water interactions and $n$ indicates the diffusion mechanism. For the value of $n=0.5$, the diffusion is Fickian, while, for Case II $n$ is equal to 1 (and Super Case II $n>1)$. For a non-Fickian or anomalous diffusion, $n$ shows an intermediate value $(0.5<n<1)$.

To determine the nature of the diffusion mechanism and the kinetics of water sorption by the composite, the diffusion constant $n$ is identified by fitting the experimental data of sorption tests with the equation:

$$
\log \left(\frac{M_{t}}{M_{\mathrm{m}}}\right)=\log k+n \log t
$$

which is derived from $E q$. 6. The values of the constants $n$ and $k$ are determined by linear regression analysis Fig. 7. For all the composites with different pretreatments, the values of the diffusion coefficient $n$ are close to 0.5 (Table 2). Consequently, water sorption of flax-reinforced composite follows a Fickian diffusion mechanism. The absorbed water content increases linearly with the square root of time and gradually approaches the equilibrium plateau. The same behavior was reported for other natural fiber-reinforced composites [9,26,27].

Transport Coefficients. The permeability of a composite material to water molecules is dependent on water diffusion as well as on water sorption. Once the Fickian nature of water sorption behavior of flax composite is known, the transport coefficients can be identified.

The diffusion coefficient $D$ characterizes the ability of water molecules to diffuse through the composite structure. For small times $\left(M_{t} / M_{\mathrm{m}} \leq 0.5\right)$, the value of diffusion coefficient $D$ can be calculated using the equation [28]:

$$
D=\frac{\pi}{\left(4 M_{\mathrm{m}}\right)^{2}}\left(\frac{M_{t} h}{\sqrt{t}}\right)^{2}=\pi\left(\frac{h \theta}{4 M_{\mathrm{m}}}\right)^{2}
$$

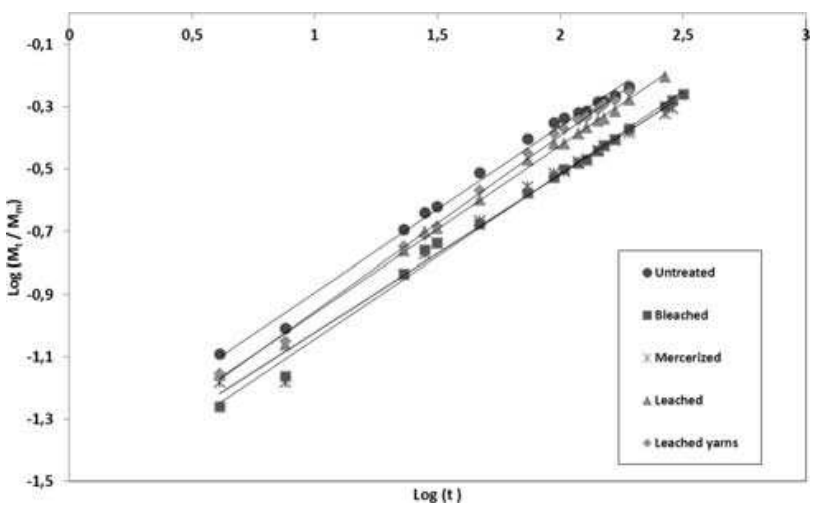

FIG. 7. Diffusion case fitting plots for flax/epoxy composite. [Color figure can be viewed in the online issue, which is available at wileyonlinelibrary.com.] 
TABLE 2. Values of the diffusion mechanism constants $n$ and $k$ for flax/epoxy composites.

\begin{tabular}{lcc}
\hline & $n$ & $k\left(h^{2}\right)$ \\
\hline Untreated & 0.533 & 0.0373 \\
Bleached & 0.528 & 0.0268 \\
Mercerized & 0.504 & 0.0297 \\
Leached & 0.536 & 0.0318 \\
Leached yarns & 0.562 & 0.0304 \\
\hline
\end{tabular}

where $h$ is the initial thickness of the samples and $\theta$ is the slope of the linear portion of the sorption curves. Generally, the pretreatments reduce the diffusion coefficient $D$ of flax/epoxy composites compared to the T3 untreated one (Table 3). The lowest values of $D$ are obtained for the composites produced using mercerized and bleached fabrics. On the opposite, the leached yarn composite has a slightly higher diffusion coefficient than that of the untreated reinforcement composite.

The sorption coefficient $S$ is calculated using the following equation [27]:

$$
\cdot S=\frac{M_{\mathrm{m}}}{M_{0}}
$$

where $M_{\mathrm{m}}$ is the mass of absorbed water at the equilibrium state and $M_{0}$ is the sample initial mass. The values of sorption coefficient $S$ of pretreated flax composites are given in Table 3. All pretreatments decrease the sorption coefficient $S$. The best results are obtained by mercerization and bleaching.

Finally, the permeability $P$ of the composite to water molecules can be considered as the net effect of sorption $S$ and diffusion $D$ :

$$
P=D S
$$

The values of the permeability coefficient of the various pretreated flax-reinforced composites are given in Table 3. Once again, except for the leached yarn pretreated composite that shows a permeability coefficient close to that of the untreated composite, it is clear that the pretreatments of reinforcement reduce the permeability of flax/epoxy composites. This decreasing of permeability may be a good indication of the improvement in fiber/matrix adhesion.

\section{Elemental Analysis by XRF and TGA}

The results of elemental analysis by XRF obtained for the five woven fabrics are given in Table 4 . The rate of organic matter (cellulose and hemicellulose $\mathrm{H}_{6} \mathrm{C}_{10} \mathrm{O}_{5}$, pectins $\mathrm{H}_{6} \mathrm{C}_{10} \mathrm{O}_{6}$ ) is superior to $99 \%$ for all samples. The results of the TGA showed a degradation peak at about $400^{\circ} \mathrm{C}$. The possible presence of wax is not visible quantitatively. The residue, measured by TGA, was less than $1 \%$, which is highly consistent with the rate of organic matter whatever the fabric (organic matter + residue rate $\sim 100 \%$ ). This validates the XRF measurements.

The ion rates of potassium $(\mathrm{K})$, calcium $(\mathrm{Ca})$, magnesium $(\mathrm{Mg})$, and sodium $(\mathrm{Na})$ are expressed in microequivalents charge per gram. It is known that these cations bound to pectins, but the calcium is mainly present on the fibers surface [29]. The cation rate of $151 \mu$ equiv. $\mathrm{g}^{-1}$, measured for untreated sample shows that the retting of this fabric is perfect. The number of charge on the fibers residual mass increases with treatment. This can be explained by the elimination of neutral polysaccharides (cellulose and hemicellulose) and to a lesser extent pectins. The primary wall and probably the first layer of the secondary wall are damaged. This is especially true for the mercerized fabric (mercerized rate $=2$ times the reference rate). The $\mathrm{Ca} / \mathrm{Mg}$ ratio decreases with treatment. This shows that the pectin is damaged at the fiber surface. This is especially true with the bleached sample $(\mathrm{Ca} / \mathrm{Mg}$ reference $=2$ times $\mathrm{Ca} / \mathrm{Mg}$ bleached).

\section{DISCUSSION}

Normally, the pretreatments are carried out with the goal of removing hydrophobic impurities from the flax fiber. Hydrophobic impurities elimination is useful to increase the water sorption of the flax fibers which, for textile industry, is essential for the wet finishing process of fabrics [17]. However, in the case of composites, pretreatments decrease the water sorption. As shown in a previous study by Sreekala et al. [9], in addition to the fiber and the matrix composition, moisture sorption depends on the fiber-matrix interface. Indeed, for the pretreated fibers, the hydrophobic impurities are removed, which increases the matrix-fiber interaction, and thus decreases the water sorption. Besides, as reported by these same authors [9], the reduction of matrix-fiber

\begin{tabular}{|c|c|c|c|}
\hline & $\begin{array}{l}\text { Diffusion coefficient, } \\
D \times 10^{7}\left(\mathrm{~mm}^{2} \mathrm{~s}^{-1}\right)\end{array}$ & $\begin{array}{l}\text { Sorption coefficient, } \\
\qquad S\left(\mathrm{~g} \mathrm{~g}^{-1}\right)\end{array}$ & $\begin{array}{l}\text { Permeability coefficient, } \\
\qquad P \times 10^{7}\left(\mathrm{~mm}^{2} \mathrm{~s}^{-1}\right)\end{array}$ \\
\hline Untreated & 8.46 & 0.233 & 1.97 \\
\hline Bleached & 3.81 & 0.167 & 0.64 \\
\hline Mercerized & 3.75 & 0.157 & 0.59 \\
\hline Leached & 5.56 & 0.182 & 1.01 \\
\hline Leached yarns & 9.21 & 0.220 & 2.02 \\
\hline
\end{tabular}

TABLE 3. Values of diffusion, sorption and permeability coefficients for flax/epoxy composite. 
TABLE 4. Results of elemental analysis by X-ray fluorescence and TGA.

\begin{tabular}{|c|c|c|c|c|c|}
\hline Fabric sample & Untreated & Leached & Leached yarn & Bleached & Mercerized \\
\hline \multicolumn{6}{|l|}{$\mathrm{XRF}$ results } \\
\hline $\mathrm{C}+\mathrm{H}+\mathrm{O}$ & 99.603 & 99.425 & 99.229 & 99.133 & 99.158 \\
\hline $\mathrm{Na}$ & 0.025 & 0.027 & 0.021 & 0.036 & 0.024 \\
\hline $\mathrm{Mg}$ & 0.023 & 0.038 & 0.055 & 0.076 & 0.067 \\
\hline $\mathrm{K}$ & 0.008 & 0.011 & 0.012 & 0.014 & 0.010 \\
\hline $\mathrm{Ca}$ & 0.238 & 0.282 & 0.420 & 0.374 & 0.459 \\
\hline Other & 0.103 & 0.218 & 0.263 & 0.368 & 0.284 \\
\hline \multicolumn{6}{|l|}{ TAG result } \\
\hline Residue rate & 0.5 & 0.596 & 0.796 & 0.978 & 0.748 \\
\hline Water & 4.2 & 4.3 & 4.0 & 4.3 & 4.5 \\
\hline Residue rate $+\mathrm{C}+\mathrm{H}+\mathrm{O}$ & 100.1 & 100.0 & 100.0 & 100.1 & 99.9 \\
\hline \multicolumn{6}{|c|}{ Cation rate in equivalent charged ( $\mu$ equiv. $\mathrm{g}^{-1}$ ) } \\
\hline $\mathrm{K}$ & 2 & 3 & 3 & 4 & 3 \\
\hline $\mathrm{Na}$ & 11 & 12 & 9 & 16 & 10 \\
\hline $\mathrm{Mg}$ & 19 & 32 & 46 & 63 & 56 \\
\hline $\mathrm{Ca}$ & 119 & 141 & 210 & 187 & 230 \\
\hline Total & 151 & 187 & 268 & 270 & 298 \\
\hline $\mathrm{Ca} / \mathrm{Mg}$ & 6.2 & 4.5 & 4.6 & 3.0 & 4.1 \\
\hline
\end{tabular}

interaction can lead to the formation of porosity within the composite, which increases the water sorption. The best results are obtained by mercerization and bleaching pretreatments. In this case, in addition to the cleaning of impurities of the fiber, these results can be explained by the activation of the hydroxyl groups of cellulose by breaking the hydrogen bond [9-13]. Consequently, the interaction enhancement between fiber and matrix decreases the water sorption. With a fiber-matrix interface of higher quality and a lower porosity fraction, water diffusion is slowed and the sorption coefficient is also reduced for pretreated flax-reinforced composites.

The experimental results for the water sorption of flax/ epoxy composites are compared with the theoretical expression of the Fick's law for a large plate of thickness $h$, where the water uptake in time is given by the following equation:

$$
\frac{M_{t}}{M_{m}}=1-\frac{8}{\pi^{2}} \sum_{n=0}^{\infty} \frac{1}{(2 n+1)} \exp \left(\frac{-(2 n+1)^{2} \pi^{2} D t}{h^{2}}\right)
$$

F8 Figure 8 shows the comparison of the experimental diffusion curve for two examples of flax fiber-reinforced composite (untreated and bleached) with the theoretical Fickian sorption model. A deviation of the experimental curve from the theoretical curve was observed, which indicates a deviation from the Fickian diffusion behavior. The same observation was reported by Joseph et al. [27]. This observation does not invalidate the discussion about transport coefficients but has to be studied in a future work.Reinforcement and porosity volume fractions have an important influence on the mechanical properties of flax-reinforced composite materials. To overcome the effect of these two factors and to quantify the reinforcement efficiency of the yarns in the composite, a calculation of the effective yarn properties (stiffness and strength) is possible. This calculation is based on the micromechanical theory applied to composite reinforced with woven fabric [30]. In this model, we assume that the twill layer is constituted of two unidirectional layers: a warp layer oriented at $0^{\circ}$ and a weft layer oriented at $90^{\circ}$. The curvature and the misalignment of yarns are not taken into account. The behavior of each layer is characterized by their elastic modulus: $E_{\mathrm{Lwarp}} ; E_{\mathrm{T} \text { warp }} ; \nu_{\mathrm{LT} \text { warp }} ; G_{\mathrm{LT} \text { warp }}$ for the warp layer and $E_{\mathrm{L} \text { weft }} ; E_{\mathrm{T} \text { weft }} ; v_{\mathrm{LT} \text { weft }} ; G_{\mathrm{LT} \text { weft }}$ for the weft layer. $E_{\mathrm{L}}$ and $E_{\mathrm{T}}$ are, respectively, the longitudinal and transversal modulus; $v_{\mathrm{LT}}$ is the Poisson's ratio and $G_{\mathrm{LT}}$ is the shear modulus.

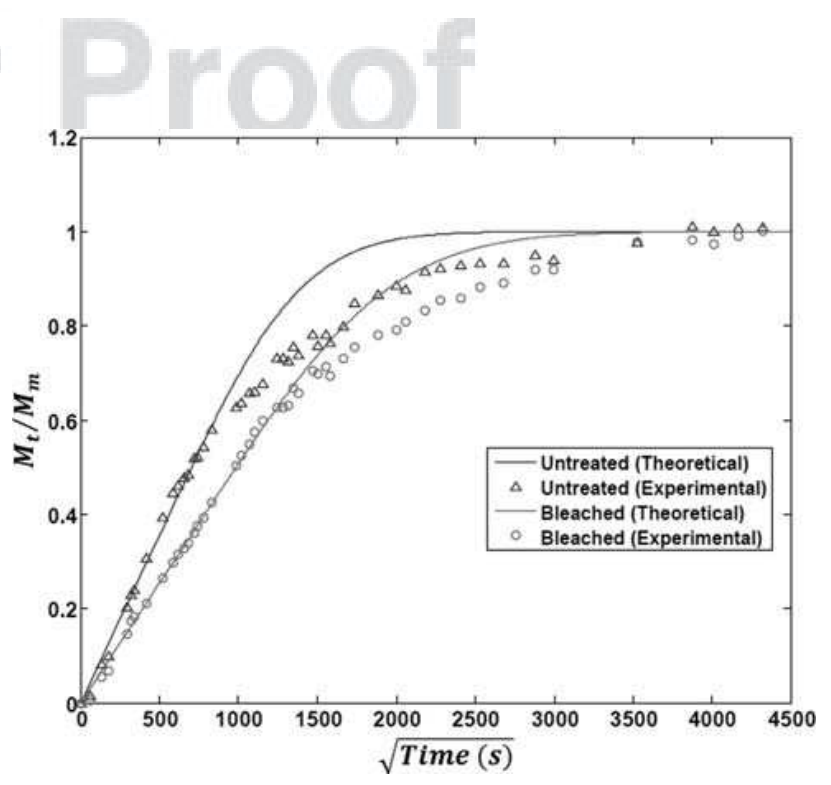

FIG. 8. Comparison between experimental and theoretical Fickian sorption curves for untreated and bleached pretreated flax-reinforced composite. [Color figure can be viewed in the online issue, which is available at wileyonlinelibrary.com.] 
The longitudinal modulus $E_{\mathrm{L}}$ comp of a laminate including a layer weft and a layer warp is calculated by the following equation:

$$
E_{\mathrm{L} \text { comp }}=(1-\alpha)\left[k_{\mathrm{G}} \alpha_{\text {warp }} E_{\mathrm{L} \text { warp }}+\left(1-k_{\mathrm{G}}\right) \alpha_{\text {weft }} E_{\mathrm{T} \text { weft }}\right]
$$

with

$$
\begin{aligned}
\alpha_{\text {warp }} & =\frac{1}{1-\frac{E_{\text {Twarp }}}{E_{\mathrm{Lwarp}}} v_{\mathrm{LT} \text { warp }}^{2}} ; \alpha_{\text {weft }}=\frac{1}{1-\frac{E_{\mathrm{T} \text { weft }}}{E_{\mathrm{Lw} \text { wt }}} v_{\mathrm{LT} \mathrm{weft}}^{2}} ; \\
k_{\mathrm{G}} & =\frac{n_{\mathrm{warp}}}{n_{\mathrm{warp}}+n_{\mathrm{weft}}}
\end{aligned}
$$

where $n_{\text {warp }}$ and $n_{\text {weft }}$ are, respectively, the number of yarns in the warp and the weft direction, $k_{\mathrm{G}}$ is a geometric ratio, and $\alpha$ is defined by the following relation:

$$
\cdot \alpha=\frac{\left[k_{\mathrm{G}} \alpha_{\text {warp }} \nu_{\mathrm{LT} \text { warp }} E_{\mathrm{T} \text { warp }}+\left(1-k_{\mathrm{G}}\right) \alpha_{\text {weft }} \nu_{\mathrm{LT} \text { weft }} E_{\mathrm{T} \text { weft }}\right]^{2}}{\frac{\left(k_{\mathrm{G}} \alpha_{\text {warp }} E_{\mathrm{L} \text { warp }}+\left(1-k_{\mathrm{G}}\right) \alpha_{\text {weft }} E_{\mathrm{T} \text { weft }}\right]\left[k_{\mathrm{G}} \alpha_{\text {warp }} E_{\mathrm{T} \text { warp }}+\left(1-k_{\mathrm{G}}\right) \alpha_{\text {weft }} E_{\mathrm{L} \text { weft }}\right]}{E_{\mathrm{L} \text { comp }}}=\frac{1}{2}\left[\left(E_{\mathrm{m}} V_{\mathrm{m}}+E_{\mathrm{r}} V_{\mathrm{r}}\right)+\left(\frac{E_{\mathrm{m}} E_{\mathrm{r}} k_{\mathrm{E}}}{E_{\mathrm{m}} V_{\mathrm{r}}+V_{\mathrm{m}} E_{\mathrm{r}} k_{\mathrm{E}}}\right)\right]}
$$

In the case where the yarns in the warp and weft directions are identical, the elastic properties in the warp and weft directions are also equal:

$$
\begin{gathered}
E_{\mathrm{L} \text { warp }}=E_{\mathrm{L} \text { weft }}=E_{\mathrm{Llayer}} ; E_{\mathrm{T} \text { warp }}=E_{\mathrm{T} \text { weft }}=E_{\mathrm{T} \text { layer }} \\
v_{\mathrm{LT} \text { warp }}=v_{\mathrm{LT} \text { weft }}=v_{\mathrm{LT} \text { layer }} .
\end{gathered}
$$

where $E_{\mathrm{Llayer}}, E_{\mathrm{T} \text { layer }}$ and $v_{\mathrm{LT} \text { layer }}$ are the elastic coefficients of an unidirectional layer with a volume fraction equal to that of the woven reference layer. Consequently, $\alpha_{\text {warp }}=\alpha_{\text {weft }}=\alpha_{\text {layer }}$ and the longitudinal modulus (Eq. 12 ) is therefore simplified as:

$$
E_{\mathrm{L} \text { comp }}=(1-\alpha) \alpha_{\text {layer }}\left[k_{\mathrm{G}} E_{\mathrm{L} \text { layer }}+\left(1-k_{\mathrm{G}}\right) E_{\mathrm{T} \text { layer }}\right]
$$

with

$$
\begin{gathered}
\alpha_{\text {layer }}=\frac{1}{1-\frac{E_{\text {Tlayer }}}{E_{\mathrm{Llayer}}} v_{\mathrm{LT} \text { layer }}^{2}} \\
\alpha=\frac{v_{\mathrm{LT} \text { layer }}^{2}}{\left[k_{\mathrm{G}} \frac{E_{\mathrm{Llayer}}}{E_{\mathrm{T} \text { layer }}}+1-k_{\mathrm{G}}\right]\left[k_{\mathrm{G}}+\left(1-k_{\mathrm{G}}\right) \frac{E_{\mathrm{Llayer}}}{E_{\text {Tlayer }}}\right]}
\end{gathered}
$$

and

It has been shown that $\alpha$ and $\alpha_{\text {layer }}$ can be rounded off to 0 and 1, respectively [30,31]. Consequently, Eq. 16 can be simplified as:

$$
E_{\mathrm{L} \text { comp }}=\left[k_{\mathrm{G}} E_{\mathrm{Llayer}}+\left(1-k_{\mathrm{G}}\right) E_{\mathrm{T} \text { layer }}\right]
$$

where $k_{\mathrm{G}}=1 / 2$ for a balanced fabric.

Properties of the composite elementary constituents are now introduced. As the twill fabric is made with flax fiber yarns, the elementary constituents are the yarn and the matrix. Therefore, the longitudinal modulus of the composite reinforced with balanced fabric $\left(k_{\mathrm{G}}=1 / 2\right)$ can be expressed using the rule of mixtures: where $E$ is the modulus, $V$ is the volume fraction and the indices $r$ and $m$ stand for yarn and for matrix, respectively, and $k_{\mathrm{E}}$ is the yarn stiffness anisotropy ratio defined as the ratio between transverse and axial stiffness of flax yarn. The first term is related to the longitudinal modulus of the layer and the second term to its transversal modulus.

Baley et al. [6] has estimated experimentally that, for flax fibers, the stiffness anisotropy ratio is comprised between $1 / 6$ and 1/8.5, whereas Cichocki and Thomason [32] obtained a value of $1 / 7$ for jute fiber. In the present work, the ratio $k_{\mathrm{E}}=1 / 7$ is used. Similarly, the ultimate stress $\sigma_{\mathrm{Lcomp}}$ is defined by Eq. 21 where we assume that the ultimate strain of the matrix is higher than that of the reinforcement.

$$
\sigma_{\mathrm{Lcomp}}=\frac{1}{2}\left[\left(\sigma_{\mathrm{r}}\left(V_{\mathrm{r}}+V_{\mathrm{m}} \frac{E_{\mathrm{m}}}{E_{\mathrm{r}}}\right)\right)+\left(\frac{\sigma_{\mathrm{m}} \sigma_{\mathrm{r}} k_{\sigma}}{V_{\mathrm{r}} \sigma_{\mathrm{m}}+V_{\mathrm{m}} \sigma_{\mathrm{r}} k_{\sigma}}\right)\right] .
$$

In this study, we assume that the yarn strength anisotropy ratio $k_{\sigma}$ is equal to $k_{\mathrm{E}}$. The rules of mixture do not take the porosity into account. The effect of porosity on stiffness and strength of natural fiber composites is efficiently taken into account by the introduction of the factor $\left(1-V_{\mathrm{p}}\right)^{x}$ in the rule of mixture [22,33-35]:

$$
\begin{aligned}
E_{\mathrm{L} \text { comp }}= & \frac{1}{2}\left[\left(E_{\mathrm{m}} V_{\mathrm{m}}+E_{\mathrm{r}} V_{\mathrm{r}}\right)+\left(\frac{E_{\mathrm{m}} E_{\mathrm{r}} k_{\mathrm{E}}}{E_{\mathrm{m}} V_{\mathrm{r}}+V_{\mathrm{m}} E_{\mathrm{r}} k_{\mathrm{E}}}\right)\right]\left(1-V_{\mathrm{p}}\right)^{x} \\
\sigma_{\mathrm{L} \text { comp }}= & \frac{1}{2}\left[\left(\sigma_{\mathrm{r}}\left(V_{\mathrm{r}}+V_{\mathrm{m}} \frac{E_{\mathrm{m}}}{E_{\mathrm{r}}}\right)\right)+\left(\frac{\sigma_{\mathrm{m}} \sigma_{\mathrm{r}} k_{\sigma}}{V_{\mathrm{r}} \sigma_{\mathrm{m}}+V_{\mathrm{m}} \sigma_{\mathrm{r}} k_{\sigma}}\right)\right] \\
& \left(1-V_{\mathrm{p}}\right)^{x}
\end{aligned}
$$

where $V_{\mathrm{p}}$ is the porosity volume fraction and $x$ is the porosity efficiency exponent. First, the effect of porosity is to decrease the load bearing volume which is 
TABLE 5. Effective mechanical properties of flax yarn with different pretreatments.

\begin{tabular}{|c|c|c|c|c|c|c|}
\hline & \multicolumn{3}{|c|}{ Effective yarn stiffness $\left(E_{\mathrm{r}}\right)$} & \multicolumn{3}{|c|}{ Effective yarn strength $\left(\sigma_{\mathrm{r}}\right)$} \\
\hline & Autoclave & Hot platen press & mean & Autoclave & Hot platen press & mean \\
\hline Untreated & $40.9 \pm 2.3$ & $43.7 \pm 1.3$ & $42.3 \pm 2.3$ & $310 \pm 7$ & $310 \pm 6$ & $310 \pm 6$ \\
\hline Bleached & $60.8 \pm 1.8$ & $55.5 \pm 2.2$ & $58.2 \pm 3.4$ & $476 \pm 12$ & $435 \pm 15$ & $460 \pm 24$ \\
\hline Mercerized & $52.4 \pm 0.9$ & $50.1 \pm 1.7$ & $51.2 \pm 1.7$ & $440 \pm 7$ & $405 \pm 21$ & $423 \pm 24$ \\
\hline Leached & $51.7 \pm 5.3$ & $52.8 \pm 1.8$ & $52.2 \pm 3.8$ & $422 \pm 19$ & $389 \pm 6$ & $405 \pm 22$ \\
\hline Leached yarns & $36.6 \pm 3.9$ & $37.4 \pm 1.9$ & $37 \pm 2.9$ & $280 \pm 9$ & $255 \pm 11$ & $267 \pm 16$ \\
\hline
\end{tabular}

introduced by reducing the yarn and matrix volumes. Second, the exponent $x$ quantifies the local stress concentration around porosities in the composite. When $x=0$, the porosity has no effect beyond lowering the load bearing volume. In this study, the porosity efficiency exponent $x$ has been identified using the experimental data. The value of $x$ has to be chosen so that the yarn stiffness and strength are independent of the porosity volume fraction $V_{\mathrm{p}}[33,36]$. Thereby, $x$ was fixed to the value 1 . The effective yarn stiffness $E_{\mathrm{r}}$ and the effective yarn strength $\sigma_{\mathrm{r}}$ are calculated from Eqs. 22 and 23, respectively.

T5 The results are given in Table 5. For a same pretreatment, the yarn effective stiffness $E_{\mathrm{r}}$ and strength $\sigma_{\mathrm{r}}$ are similar regardless of the process used for composite elaboration. Therefore, the yarn effective properties are independent of the elaboration process and only depend on the intrinsic yarn properties and the yarn-matrix interface. Consequently, for each pretreatment, a mean value of the effective yarn stiffness $E_{\mathrm{r}}$ and strength $\sigma_{\mathrm{r}}$ is calculated Table 5. To facilitate the comparison, pretreatment effect on yarn effective properties is expressed relatively to the

F9 untreated yarn properties (Fig. 9). The best effect is reached with bleaching pretreatment with an effective yarn stiffness of $58.2 \mathrm{GPa}$ which indicates an improvement of $37 \%$. For mercerization and leaching pretreatments, the yarns effective stiffness is, respectively, 51.2 and $52.2 \mathrm{GPa}$, which means an enhancement of 21 and
$23 \%$. For the leached yarns composite, $E_{\mathrm{r}}$ is lower than that with untreated reinforcement composite with a decrease of about $13 \%$. This is due to their low quality (yarn made with scutching and hackling tows). For the effective yarn strength, the best result is also obtained with bleaching pretreatment with a value of $460 \mathrm{MPa}$ and an increase up to $48 \%$. Mercerization and leaching pretreatment show an improvement of 36 and $31 \%$, respectively. $\sigma_{\mathrm{r}}$ given by the composite produced with leached yarns is also lower compared to that of untreated yarn. In this case, the reduction is estimated at $14 \%$.

Therefore, it is obvious that conventional textile treatments are a powerful way to improve the mechanical properties of flax yarn-reinforced composites. The strength improvement reaches $55 \%$ with bleaching or mercerization. Our results prove that after pretreatment, the reinforcement induced by the yarns is enhanced. The reinforcement effect within the composite comes from the intrinsic yarn properties and the yarn-matrix interface. Tensile tests on flax dry fabric show that treatments reduce the mechanical properties of yarns. The strength decrease reached $40 \%$. Three effects explain this decrease. The reduction of the intrinsic properties of the elementary fibers is the first effect [24], which is explained via XRF measurements by polysaccharides degradation in the fiber surface. The separation of the individual fibers in the bundles is the second effect. This

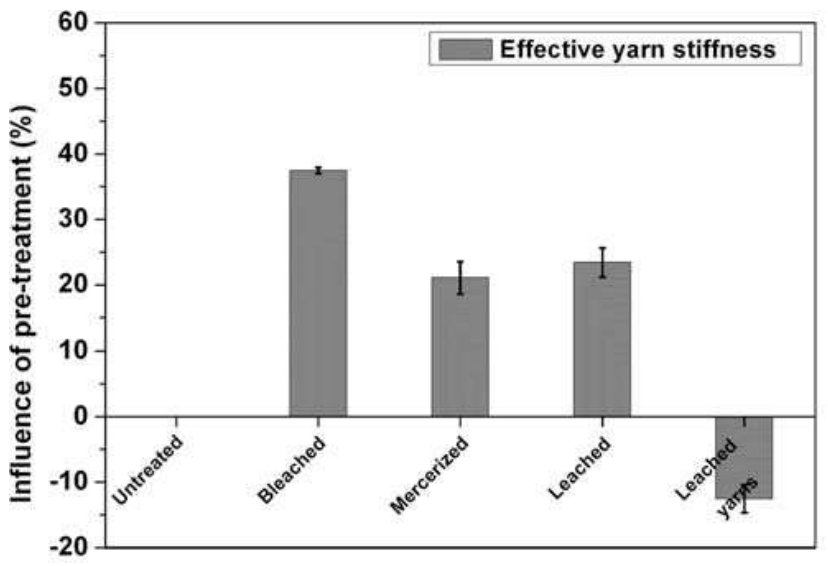

(a)

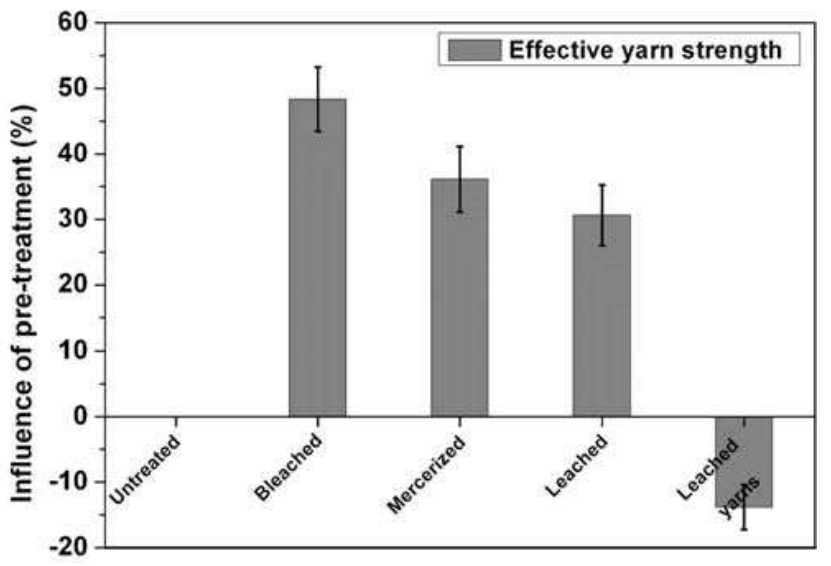

(b)

FIG. 9. Influence of pretreatments on the effective yarn properties, compared to untreated yarn. (a) Stiffness and (b) strength. 


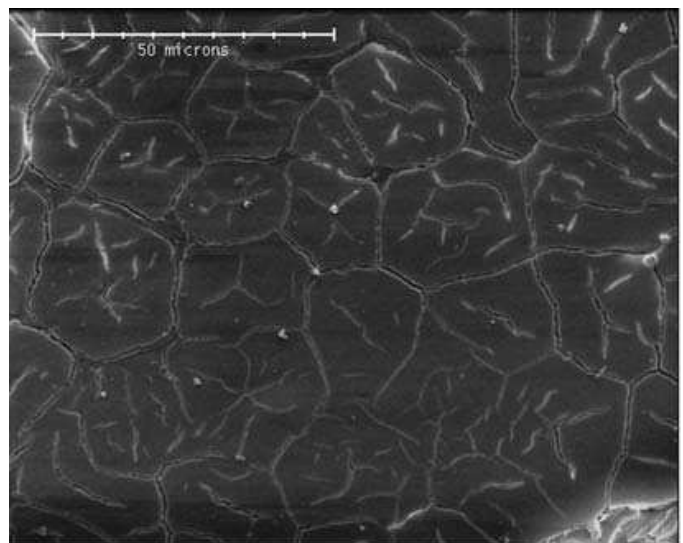

(a)

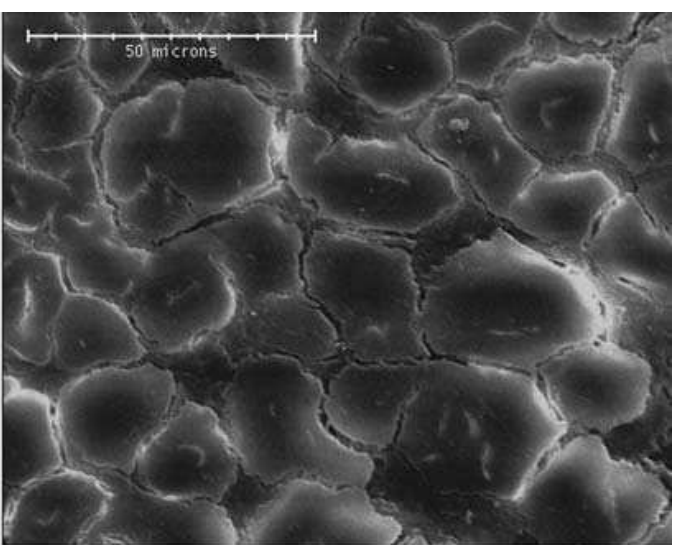

(b)

FIG. 10. Scanning electron micrograph of flax/epoxy composite: (a) untreated and (b) mercerized.

separation is explained via XRF measurements by pectins degradation at the fibers surface. It has the effect of reducing the average length of elementary reinforcement. Indeed, originally flax fibers form long bundles of several decades of fibers [37]. The individual fibers separation is first started by the initial transformation process (retting), and the chemical pretreatments complete this fibers separation. The third effect is the modification of surface properties of elementary reinforcements [38,39]. This last effect could act positively on the mechanical properties of dry yarn by improving the adhesion between the elementary reinforcements.

Consequently, to obtain the reinforcement effect of the composite, the yarn-matrix interface has to be improved. The interface is modified at three levels. First, pretreatments allow the cleaning of fiber and yarn surfaces by eliminating impurities (waxes, fats, proteins, and inorganic substances) [17]. Second, we have seen that pretreatments facilitate the fiber separation. Unlike the untreated sample where we observe a bundle of nonsepa-

F10 rated fibers inside the yarn (Fig. 10), in pretreated samples fibers are separated. In this case, resin penetration between fibers is facilitated. Finally, during composite elaboration, the weak natural connections between the fibers assumed by pectins are replaced by fiber-matrix interface bondings. The fracture surface of the composite with untreated yarns and pretreated yarns are shown in Fig. 11. For the pretreated sample, we observe the presence of matrix on fibers. This observation confirms the penetration of matrix inside the yarns and the good adhesion of the matrix on the reinforcement, contrary to the case of the untreated sample. Finally, treatments roughly increase the efficiency of the load transfer between reinforcement and matrix.

\section{CONCLUSIONS}

This work has shown the influence of the conventional textile treatment of flax fibers on the mechanical and moisture sorption of flax/epoxy composites. These fiber surface treatments improve the mechanical properties (strength and stiffness) of these materials. This is due to the improvement in adhesion between matrix and fibers.

The water sorption studies show that water uptake of flax/epoxy is reduced after pretreatment which can also be explained by a better interfacial bonding between fiber

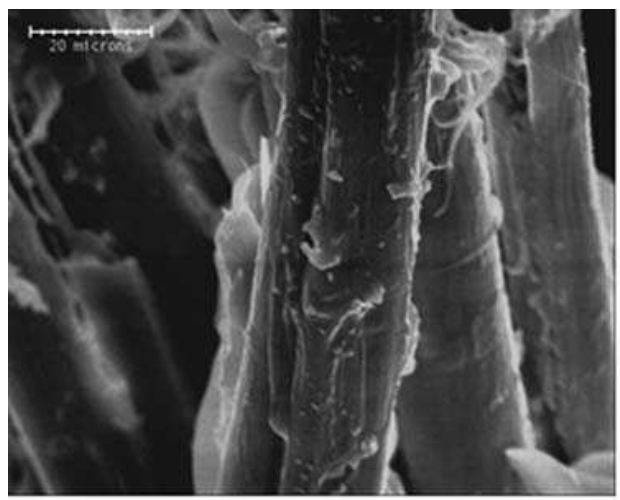

(a)

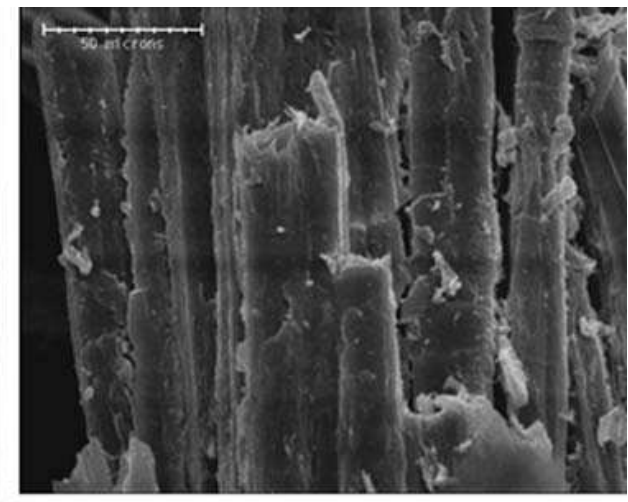

(b)

FIG. 11. Scanning electron micrographs of fracture surfaces of flax/epoxy composite: (a) untreated and (b) mercerized. 
and matrix. Diffusion coefficient, sorption coefficient, and permeability coefficient also decreased after the pretreatment.

It is know that alkali pretreatments remove the impurities from the fibers surface. Moreover, elemental analysis by XRF shows that they facilitate the separation of fibers by damaging pectins in surface. Moreover, the weak natural connections between the fibers assumed by pectins are replaced by fiber-matrix interface bonding. Elemental analysis by XRF shows also that alkali pretreatments decrease the properties of elementary fibers by damaging polysaccharides in surface.

The competition between all the effects is in favor to amelioration of reinforcement/matrix interface. The best results in mechanical properties and water sorption resistance are achieved with mercerization and bleaching pretreatments. Unlike leaching pretreatment, the hydroxyl groups on flax fiber surface are activated which allows further increasing of fiber-matrix interaction.

In contrast, the weakest performances are achieved with composite made from a fabric of short fiber leached yarns. In this case, even if leaching treatment is efficient to improve interface bonding, it is not sufficient to offset the decrease in fiber mechanical properties.

\section{ACKNOWLEDGMENTS}

LINEO NV Company is gratefully acknowledged for providing of all the prepregs. Claudine Morvan is warmly thanked for the very helpful discussion.

\section{REFERENCES}

1. K. Van de Velde and P. Kiekens, Die Angew. Makromol. Chem., 272 (1999).

2. A.K. Bledzki and J. Gassan, Prog. Polym. Sci., 24 (1999).

3. B.V. Kokta, R.G. Raj, and C. Daneault, Polym. Plast. Technol. Eng., 28 (1989).

4. J.M. Felix and P. Gatenholm, J. Appl. Polym. Sci., 42 (1991).

5. C. Baley, F. Bunsel, Y. Grohens, and O. Sire, Composites Part A, 37 (2006).

6. C. Baley, Y. Perrot, F. Busnel, H. Guezenoc, and P. Davies, Mater. Lett., 60 (2006).

7. I. Van de Weyenberg, J. Ivens, A. De Coster, B. Kino, E. Baetens, and I. Verpoest, Compo. Sci. Technol., 63 (2003).

8. G. Cantero, A. Arbelaiz, R. Llano-Ponte, and I. Mondragon, Compo. Sci. Technol., 63 (2003).

9. M.S. Sreekala, M.G. Kumaran, and S. Thomas, Composites Part A, 33 (2002).

10. J. Gassan and A.K. Bledzki, Compo. Sci. Technol., 59 (1999).

11. A.K. Mohanty, M. Misra, and G. Hinrichsen, Macromol. Mater. Eng., 276/277 (2000).

12. C.A.S. Hill and H.P.S. Abdul Khalil, J. Appl. Polym. Sci., 78 (2000).
13. P.A. Sreekumar, S.P. Thomas, J.M. Saiter, J. Kuruvilla, G. Unnikrishnan, and S. Thomas, Composites Part A, 41 (2009).

14. A. Arbelaiz, B. Fernández, J.A. Ramos, A. Retegi, R. Llano-Ponte, and I. Mondragon, Compo. Sci. Technol., 65 (2005).

15. Y. Li, M. Sreekala, M. Jacob, "Textile composites based on natural fibers," in Natural Fiber Reinforced Polymer Composites: From Macro to Nanoscale, S. Thomas and L.A. Pothan, Eds., Old City Publishing, Philadelphia, 202 (2009).

16. http://www.lineo.eu/. Accessed June 25, 2013.

17. D. Fakin, V. Golob, K. Stana Kleinschek, and A. Majcen Le Marechal, Text. Res. J., 76 (2006).

18. J. Van Raemdonck, inventor, Patent WO/2007/025782 (2007).

19. http://www.huntsman.com/. Accessed June 25, 2013.

20. C. Poilâne, A. Vivet, L. Momayez, B. Ben Doudou, M. Ayachi, and J. Chen, Proceeding Compte rendu des JNC16. Toulouse, June, 1 (2009).

21. Z.E. Cherif, PhD Thesis, The Caen Basse-Normandy University, Caen, France (2013).

22. B. Madsen and H. Lilholt, Compo. Sci. Technol., 63 (2003).

23. J.L. Thomason, Composites, 26 (1995).

24. Y. Li and K.L. Pickering, Compo. Sci. Technol., 69 (2009).

25. J. Comyn, Polymer Permeability, Chapman \& Hall, London, UK (1985).

26. A. Espert, F. Vilaplana, and S. Karlsson, Composites Part A, 35 (2004).

27. P.V. Joseph, M.S. Rabello, L.H.C. Mattoso, K. Joseph, and S. Thomas, Compo. Sci. Technol., 62 (2002).

28. J. Cranck, The Mathematics of Diffusion, Clarendon Press, Oxford, UK (1979).

29. C. Morvan, C. Andème-Onzighi, R. Girault, D.S. Himmelsbach, A. Driouich, and D.E. Akin, Plant Physiol. Biochem., 41 (2003).

30. J.M. Berthelot, Composite Materials: Mechanical Behavior and Structural Analysis, Springer-Verlag, New York (1999).

31. C. Bonnafous, PhD Thesis, The National School of Mechanics and Aerotechnics, Poitier, France (2010).

32. F.R. Cichocki and J.L. Thomason, Compo. Sci. Technol., 62 (2002).

33. H. Toftegaard and H. Lilholt, Proceedings of the 23rd Risø International Symposium on Materials Science. Roskilde, September, 325 (2002).

34. A. Thygesen, A.B. Thomsen, G. Daniel, and H. Lilholt, Ind. Crops Prod., 7 (2007).

35. J. Summerscales, N. Dissanayake, A. Virk, and W. Hall, Composites Part A, 41 (2010).

36. A. Thygesen, PhD Thesis, The Royal Veterinary and Agricultural University, Copenague (2005).

37. C. Baley, Composites Part A, 33 (2002).

38. I. Van de Weyenberg, T. Chi Truong, B. Vangrimde, and I. Verpoest, Composites Part A, 37 (2006).

39. S.H. Aziz and M.P. Ansell, Compo. Sci. Technol., 64 (2004). 